\title{
ACTIVITY OF DAILY LIVING ON NON-WORKING AND WORKING DAYS IN POLISH URBAN SOCIETY
}

\section{KATARZYNA WESOLOWSKA and BOZENA CZARKOWSKA-PACZEK}

\author{
Medical University of Warsaw, Warszawa, Poland \\ Department of Clinical Nursing
}

\begin{abstract}
Objectives: Activities of daily living are currently the simplest form of activity. For many people this is the only activity in which they participate. In this connection, it is important to determine the level of physical activity connected with daily habits including occupational activities. The main goal of the presented study has been to assess the level of activities of daily living in different age groups and its differentiation by season and working (WD) and non-working days (NWD). Material and Methods: The study group (urban citizens, $\mathrm{N}=106)$ was divided into young $(\mathrm{Y})(\mathrm{N}=40)$, middle-aged $(\mathrm{M})(\mathrm{N}=38)$, and senior $(\mathrm{S})(\mathrm{N}=28)$ participants. The daily step number on 7 consecutive days during 4 seasons between June 2012 and 2013 was counted objectively using pedometers. The long-form of the International Physical Activity Questionnaire (IPAQ) was completed each season as a subjective assessment. Results: The daily step number for the whole group for the year was (median) 6615 (range: 3648-10 709), fewer than recommended. The median (Me) was highest in group $\mathrm{M}(\mathrm{Me}=6994$, range: 3648-10 709) followed by $\mathrm{Y}(\mathrm{Me}=6957$, range: 4094-10 321) and S $(\mathrm{Me}=5469$, range: 3743-8955). The lowest daily step number occurred in winter $(M=6208, Y=6063, S=5242)$, and the highest in spring $(\mathrm{Y}=7385)$ or summer $(\mathrm{M}=7717 ; \mathrm{S}=6095)$. All groups had a greater daily step number on WDs compared to NWDs (Y: 8411 vs. 5744, M: 7612 vs. 5839, S: 6327 vs. 4580; p < 0.01 for all). Pedometer-tracked values did not correlate with the IPAQ results. Conclusions: Activity level in Polish urban society is low, especially on NWDs and in colder months. The daily number of steps is highest in the middle-aged group, which may be connected with working status. Objective methods are recommended for assessing physical activity level. Int J Occup Med Environ Health 2018;31(1):47-54
\end{abstract}

Key words:

IPAQ, Urbanization, Health behavior, Sedentary behavior, Physical activity level, Occupational physical activity

\section{INTRODUCTION}

Physical activity as a prevention method against chronic diseases is already well established. Although the World Health Organization (WHO) recommendations on the use of physical activity in chronic disease prevention are generally known [1], a large number of people still lead a sedentary lifestyle. As many as a quarter of the U.S. adults do not engage in any physical activity during their leisure time [2], and 31\% of the world population does not meet the WHO's minimum physical activity recommendations. Physical inactivity is the fourth leading cause of death worldwide [3] and it was considered one of the most important public health problems of the 21st century [4]. In 2007, the estimated 5.3 to 5.7 million of all deaths caused by non-communicable diseases could have been prevented by increasing physical activity [3]. Nowadays

Received: July 24, 2016. Accepted: November 9, 2016.

Corresponding author: K. Wesolowska, Medical University of Warsaw, Department of Clinical Nursing, Ciołka 27, 01-445 Warszawa, Poland (e-mail: wesolowska_katarzyna@wp.pl). 
it is well-established that physical inactivity increases the risk of type 2 diabetes, cardiovascular diseases, colon cancer and postmenopausal breast cancer. These diseases constitute a network of related diseases, also called "the diseasome of physical inactivity" [5].

The promotion of an active lifestyle is undoubtedly still necessary, but the physical activity recommendations should refer mostly to periods when activity level is particularly low. A high level of activity of daily living has a positive effect on general health, and activity in the workplace, at home, and during the commute and the total activity per day reduces the risk of mortality from cardiovascular disease [6,7]. A similar relationship has been demonstrated between activity and mortality risk from cancer and overall mortality [6-9].

It has been suggested that the WHO guidelines on the use of physical activity in the prevention of chronic diseases, i.e., $30 \mathrm{~min}$ of moderate-intensity exercise no fewer than 5 days a week [1], may be successfully replaced with a specified number of steps per day, which is 10000 for adults. The daily walking activity has been classified as sedentary when the daily number of steps was fewer than 5000, low active - between 5000 and 7499, and somewhat active - between 7500 and 10000 [10,11].

Currently, various methods are used for the evaluation of physical activity level, including application of the International Physical Activity Questionnaire (IPAQ) [12]. Reports have indicated that subjective assessment made using this form may be used interchangeably with an objective assessment using, for example, a pedometer [13] to count daily steps.

The aim of this cross-sectional study thus has been to assess the daily number of steps in 3 age groups from a Polish population during both working days and non-working days in all 4 seasons of the year. This information, in addition to indicating when level of activity is lowest and should be promoted with greater intensity, was compared with results for the subjective IPAQ assessment, with the level of daily activity expressed in the metabolic equivalent of task (MET) values.

\section{MATERIAL AND METHODS}

The Ethics Committee of the Medical University of Warsaw, Poland, approved the experimental protocol (No. KB9/2012). All participants signed written consents to participate in the study.

The groups investigated in this cross-sectional study comprised 106 healthy volunteers, urban citizens of both sexes (women: $\mathrm{N}=63$, men: $\mathrm{N}=43$ ) divided into 3 age groups: young $(\mathrm{Y}$; age - median $(\mathrm{Me})=24$ years old, range: 22 26 years old), middle aged $(\mathrm{M}$; age $-\mathrm{Me}=39$ years old, range: $27-59$ years old $)$, and senior $(\mathrm{S}$; age $-\mathrm{Me}=72$ years old, range: 60-86 years old). Participant characteristics are presented in the Table 1.

The exclusion criteria were assessed based on an interview, urinalysis, and blood analysis and included cancer, stroke, a history of heart attack or presence of a pacemaker, post-traumatic conditions, chronic pain impeding pedestrian locomotion, infectious diseases, diabetes, endstage liver or renal failure, asthma, chronic obstructive pulmonary disease, use of more than 2 blood pressureregulating drugs, and pregnancy.

The level of daily physical activity was evaluated using a pedometer (Silva Ex Connect, produced by Silva Sweden $\mathrm{AB}$ ) for 7 consecutive days during 4 seasons. The assessments took place between June 2012 and June 2013. In the evaluation, data from 5 working days and 2 non-working days was considered. On this basis, the average daily number of steps on weekdays and weekends was calculated. Dates for the study were selected not to include work holidays, vacations, sudden absence from work or university, and sickness.

Participants were asked to maintain existing habits of daily activities in every aspect of life, including household chores, leisure time activities, activities at work, and engagement in the community. Participants were asked to 
Table 1. Characteristics of the study groups in the assessment of the level of activities of daily living amongst urban citizens, June 2012 to June 2013

\begin{tabular}{lccccccc}
\hline \multirow{2}{*}{$\begin{array}{c}\text { Respondents } \\
\left(\mathrm{N}=106^{\mathrm{a}}\right)\end{array}$} & \multicolumn{9}{c}{ Characteristics } \\
\cline { 2 - 7 } & \multicolumn{2}{c}{$\begin{array}{c}\text { age } \\
\text { [years] }\end{array}$} & \multicolumn{2}{c}{$\begin{array}{c}\text { body weight } \\
{[\mathrm{kg}]}\end{array}$} & \multicolumn{2}{c}{$\begin{array}{c}\text { body mass index } \\
(\mathrm{BMI})\end{array}$} \\
\cline { 2 - 8 } & $\mathrm{Me}$ & $\min .-\mathrm{max}$ & $\mathrm{Me}$ & min.-max & Me & min.-max \\
\hline Young $\left(22-26\right.$ years old, $\left.\mathrm{N}=40^{\mathrm{b}}\right)$ & 24.00 & $22.0-26.0$ & 68.00 & $43.9-103.8$ & 21.95 & $17.6-32.6$ \\
Middle-aged $\left(27-59\right.$ years old, $\left.\mathrm{N}=38^{\mathrm{c}}\right)$ & 39.00 & $27.0-59.0$ & 79.85 & $48.3-112.4$ & 24.20 & $18.4-36.3$ \\
Senior $\left(60-86\right.$ years old, $\left.\mathrm{N}=28^{\mathrm{d}}\right)$ & 72.00 & $60.0-86.0$ & 71.65 & $52.6-90.1$ & 26.65 & $20.6-35.2$ \\
\hline
\end{tabular}

a Women: $\mathrm{N}=63$, men: $\mathrm{N}=43$.

${ }^{\mathrm{b}}$ Women: $\mathrm{N}=20$, men: $\mathrm{N}=20$.

${ }^{c}$ Women: $\mathrm{N}=21$ men: $\mathrm{N}=17$.

${ }^{\mathrm{d}}$ Women: $\mathrm{N}=22$, men: $\mathrm{N}=6$.

$\mathrm{Me}$ - median; min. - minimal value; max - maximal value.

place the pedometer around the hip belt just after waking up and to take it off just before bedtime.

The pedometer could be removed only for bathing. If any of the assessed days was missed, the person was asked to extend the study by one working day or non-working day, as required. Simultaneously with the objective assessment of activity level using the pedometer, a subjective assessment using the long-form International Physical Activity Questionnaire (IPAQ) in each of the seasons was made. Total times engaged in walking, moderate physical activity, and vigorous physical activity were computed according to guidelines [14].

The statistical analysis was performed using Statistica 10 software. All data is expressed as the median and range. The Kruskal-Wallis one-way analysis of variance by ranks was used for analyzing differences between study groups. The difference between the daily number of steps in working days and non-working days was evaluated using the Wilcoxon signed-rank test. Spearman correlation coefficients were calculated to assess the relationship between step counts and questionnaire-based physical activity. $\mathrm{P}$ values less than 0.05 were considered statistically significant.

\section{RESULTS}

The median value for the daily number of steps in the whole group during the whole year was 6615 (range: 3648-10 709). Median values for the average daily number of steps in each age group are shown in the Table 2. The Kruskal-Wallis one-way analysis of variance by ranks showed a significant difference between study groups ( $p=0.0002 ; H=17.34527)$. Multiple comparison of mean ranks showed significant differences between the seniors group and the middle-aged group ( $p=0.00286$, $\mathrm{z}=3.30409)$ and between the seniors group and the young group ( $p=0.00022, z=3.96665)$. The results have shown that the daily number of steps is lowest in the seniors group and does not significantly differ between the young group and the middle-aged group, which means that is similar. Median values and ranges of the average daily number of steps in the 4 seasons of the year are shown in the Table 3. The daily number of steps differed significantly between seasons in the young group $\left(\mathrm{p}=0.00082\right.$, $\left.\mathrm{Chi}^{2} \mathrm{ANOVA}=16.68\right)$, in the middle-aged group $\left(\mathrm{p}=0.00222, \mathrm{Chi}^{2} \mathrm{ANOVA}=14.5784\right)$ and in the seniors group $\left(\mathrm{p}=0.00731, \mathrm{Chi}^{2} \mathrm{ANOVA}=12.0207\right)$. The highest number of steps was noted in the summer and spring season in all study groups. 
Table 2. Average daily number of urban citizens' steps throughout the year, June 2012 to June 2013

\begin{tabular}{lcc}
\hline \multicolumn{1}{c}{$\begin{array}{c}\text { Respondents } \\
\left(\mathrm{N}=106^{\mathrm{a}}\right)\end{array}$} & \multicolumn{2}{c}{$\begin{array}{c}\text { Steps } \\
{[\mathrm{n} / \text { day }]}\end{array}$} \\
\cline { 2 - 3 } & $\mathrm{Me}$ & $\min$--max \\
\hline Young $\left(22-26\right.$ years old, $\left.\mathrm{N}=40^{\mathrm{b}}\right)$ & 6957 & $4094-10321$ \\
Middle-aged $\left(27-59\right.$ years old, $\left.\mathrm{N}=38^{\mathrm{c}}\right)$ & 7342 & $3648-10709$ \\
Senior $\left(60-86\right.$ years old, $\left.\mathrm{N}=28^{\mathrm{d}}\right)$ & 5390 & $3743-8955$ \\
\hline
\end{tabular}

Explanations as in Table 1.

Table 3. Average daily number of participants' steps in successive seasons, June 2012 to June 2013

\begin{tabular}{|c|c|c|c|c|c|c|c|c|}
\hline \multirow{3}{*}{$\begin{array}{l}\text { Respondents } \\
\left(\mathrm{N}=106^{\mathrm{a}}\right)\end{array}$} & \multicolumn{8}{|c|}{$\begin{array}{l}\text { Steps } \\
\text { [n/day] }\end{array}$} \\
\hline & \multicolumn{2}{|r|}{ summer } & \multicolumn{2}{|c|}{ autumn } & \multicolumn{2}{|r|}{ winter } & \multicolumn{2}{|r|}{ spring } \\
\hline & $\mathrm{Me}$ & $\min .-\max$ & $\mathrm{Me}$ & $\min .-\max$ & $\mathrm{Me}$ & $\min .-\max$ & $\mathrm{Me}$ & $\min .-\max$ \\
\hline Young $\left(22-26\right.$ years old, $\left.\mathrm{N}=40^{\mathrm{b}}\right)$ & 7071 & 4 319-12 094 & 6819 & $3256-14407$ & 6063 & $3525-16188$ & 7385 & $4685-14400$ \\
\hline Middle-aged $\left(27-59\right.$ years old, $\mathrm{N}=38^{\mathrm{c}}$ ) & 7717 & $2341-15113$ & 6441 & $2609-13136$ & 6208 & $3469-15514$ & 6372 & $3290-15192$ \\
\hline Senior (60-86 years old, $\mathrm{N}=28^{\mathrm{d}}$ ) & 6095 & $3822-10096$ & 5288 & $3104-9643$ & 5242 & $3368-12514$ & 5475 & $3404-11069$ \\
\hline
\end{tabular}

Explanations as in Table 1.

Table 4. Average daily number of urban citizens' steps on working days (WD) and non-working days (NWD), June 2012 to June 2013

\begin{tabular}{|c|c|c|c|c|}
\hline \multirow{3}{*}{$\begin{array}{c}\text { Respondents } \\
\left(\mathrm{N}=106^{\mathrm{a}}\right)\end{array}$} & \multicolumn{4}{|c|}{$\begin{array}{c}\text { Steps } \\
\text { [n/day] }\end{array}$} \\
\hline & \multicolumn{2}{|c|}{ WD } & \multicolumn{2}{|c|}{ NWD } \\
\hline & $\mathrm{Me}$ & $\min .-\max$ & $\mathrm{Me}$ & $\min .-\max$ \\
\hline Young (22-26 years old, $\mathrm{N}=40^{b}$ ) & 8411 & $4515-11467$ & 5744 & $2997-11502$ \\
\hline Middle-aged (27-59 years old, $\left.\mathrm{N}=38^{\mathrm{c}}\right)$ & 7612 & $3690-12993$ & 5839 & $3502-10207$ \\
\hline Senior $\left(60-86\right.$ years old, $\left.N=28^{d}\right)$ & 6327 & $3999-9544$ & 4580 & $3143-8436$ \\
\hline
\end{tabular}

Explanations as in Table 1.

Median values and ranges of the average daily number of steps on working days and non-working days (holidays) are shown in the Table 4. Wilcoxon test results showed statistically significant differences between the average daily number of steps during working days and non-working days in all groups (group Y: $\mathrm{p}=0.000004$, $\mathrm{Z}=4.62381$; group $\mathrm{M}: \mathrm{p}=0.000004, \mathrm{Z}=4.6390329$; and group $S: p=0.000003, Z=4.6814231)$. The daily num- ber of steps was lower on non-working days in all study groups.

Comparison of the objectively measured average daily number of steps with the assessment of the level of physical activity measured using the IPAQ questionnaire in the various seasons in the whole study group showed no statistically significant correlation in any of the evaluated seasons. The correlation plot of average values from the 


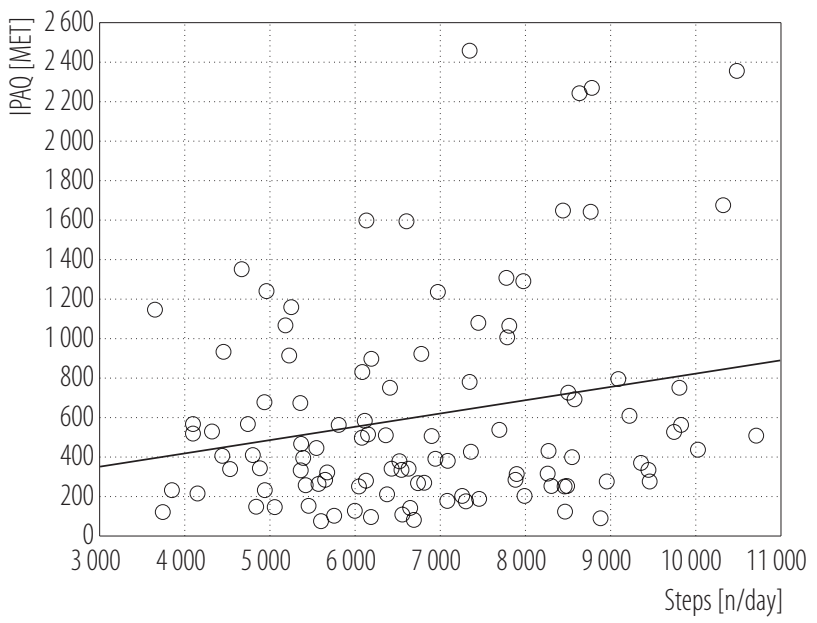

MET - metabolic equivalent of task; IPAQ - International Physical Activity Questionnaire.

Fig. 1. Correlation plot of average daily number of steps and the self-measured physical activity level of urban citizens, June 2012 to June 2013

whole year is presented in the Figure 1. The results suggest that there has been no relationship between subjective and objective assessment.

\section{DISCUSSION}

The most important finding of our study is that the level of activities of daily living is lower on non-working days than during working days in all studied groups. This result conflicts with the common belief that physical activity is more likely to be performed in leisure time than during working days. These results also differ from those of Mitsui et al. [15] showing that office workers are more active on non-working days than on working days during summer, with an inverse pattern in the winter season. The authors suggest that the number of daily steps taken by participants in their study was not reduced on holidays, because they were not active on workdays, due to the fact that most of them were desk workers who commuted in private cars and some participants enjoyed walking or hiking on holiday [15].

However, the findings of another study of white collar workers in Tokyo are in agreement with our results. Au- thors have shown that commuters who use public transportation usually engage in more physical activity on workdays than on holidays [16]. This finding shows that for many people living in urban societies, activity connected with professional work and daily duties is the only activity in which they participate.

The second important outcome of the study is the lack of correlation between the objective pedometer values and the subjective IPAQ scores. The fact that there has been no statistically significant correlation between the parameters described in any of the evaluated seasons indicates that study participants could not correctly assess their own level of physical activity.

This result is consistent with a previous study, in which changes of daily physical activity measured by the IPAQ and an accelerometer were largely uncorrelated. Authors concluded that the IPAQ did not have any acceptable level of sensitivity and specificity when compared with objective assessments [17]. The use of evaluation forms for physical activity is popular; however, these forms provide only a subjective assessment, and as it is clear from this study, they may differ from an objective assessment. Thus, objective methods are recommended, based on our findings.

These results diverge, though, from those of a study comparing various questionnaires for assessing physical activity and an objective assessment using a pedometer, which has found a high correlation between the number of objectively counted steps and the overall level of activity as assessed using the IPAQ [13]. On the other hand, other studies have shown unrealistically high levels of physical activity measured by the IPAQ. Authors conclude that those high levels of overestimation of self-reported daily activity greatly reduce the utility of this instrument [18]. The daily number of steps in representative age groups in our study is lower than the recommended 10000 steps, a finding that is consistent with reports from other urbanized countries [19]. Particularly low values for the daily number of steps are observed in the oldest age group, which also confirms 
available reports [19-23]. Although the recommendations for the daily number of steps for the elderly are lower than for younger adults, at about 8000 steps per day, the amounts identified in this study still do not meet generally accepted recommendations [20], which emphasizes the need to increase physical activity levels in this age group.

Among the factors associated with a decrease in the level of activity in the elderly were: older age, female gender, obesity, health problems, disability, pain, depression, smoking, low levels of education, social isolation, low motivation, bad weather and dangerous neighborhood [23], but in this study, people with health problems, pain and dysfunctions were excluded from the study group. Therefore, it seems that the most important factor which may affect a gradual decrease in physical activity with aging is low motivation.

Global declines in physical activity have been attributed to economic development, with the subsequent increase in urbanization [24] and communication technologies [25]. This finding may be supported by an other study, in which authors have shown that the most active society are Canadian Amish, which have elected to keep most types of modern technology out of their lives $[19,26]$.

The lowest level of activities of daily living occurred in the winter season in this study, in all groups; however, activity in warmer months was also low. Other authors have also reported a decline in activity in the autumn-winter season, among adults [27], among children [28] and adult white collar workers [16]. We conclude that public health initiatives should target these seasonal differences, to encourage individuals to increase their activity levels during the winter months.

Undoubtedly, physical activity should be promoted among all age groups, especially among the elderly and with a special emphasis in the colder months. An excellent way to increase physical activity is to use the daily threshold of the number of steps. People who are asked to achieve $30 \mathrm{~min}$ of middle intensity walking per day are less likely to increase their physical activity level than those who have a daily 10000 -step goal [29]. The use of a pedometer in increasing physical activity may be beneficial in, e.g., patients who have contraindications to intense exercise or those less motivated to undertake physical activity. The applied method is inexpensive, and the results are reproducible and give excellent feedback. Such interventions are important in the prevention of non-communicable diseases, particularly cardiovascular disease [30].

This study has several limitations. Firstly, the possible presence of activities immeasurable by a pedometer, such as swimming or cycling. Although none of the participants declared activity other than walking, the use of a pedometer in assessing the overall level of physical activity or daily energy expenditure without any form of interview may be flawed. On the other hand it has been shown that using a pedometer may motivate subjects to increase their physical activity, which could result in improved measurements. Among the strengths is the fact, that this study is the first assessment of the level of activity of daily living in Poland, measured by the objective method during all seasons. This data may be used for the comparative analysis of activities of daily living from various urbanized countries.

\section{CONCLUSIONS}

The pattern of daily activity could differ among nations because of varying cultural and environmental conditions and particular habits. However, promoting an increase in activities of daily living is necessary, particularly for the elderly and in colder months. A disturbing finding of our study is that activity also needs to be promoted during the summer, in spite of greater activity levels in this season compared to the rest of the year. It is also very important to increase activity especially on non-working days. Properly assessed physical activity level should play an important part because a subjective assessment is inconsistent with objective findings. Relying on subjective perceptions may lead to a decrease in activity if those at whom recom- 
mendations target incorrectly evaluate physical activity as high and do not follow the recommendations. It is advisable to use methods of increasing physical activity that offer objective feedback, such as a pedometer.

\section{REFERENCES}

1. World Health Organization. Global recommendations on physical activity for health [Internet]. Geneva: The Organization; 2010 [cited 2016 June 9]. Available from: http://www. who.int/dietphysicalactivity/publications/9789241599979/en.

2. Bravata DM, Smith-Spangler C, Sundaram V, Gienger AL, Lin N, Lewis R, et al. Using pedometers to increase physical activity and improve health: A systematic review. JAMA. 2007;298:2296-304, https://doi.org/10.1001/jama.298.19.2296.

3. Kohl HW, Craig CL, Lambert EV, Inoue S, Alkandari JR, Leetongin $\mathrm{G}$, et al. The pandemic of physical inactivity: Global action for public health. Lancet. 2012;380:294-305, https:// doi.org/10.1016/S0140-6736(12)60898-8.

4. Blair SN. Physical inactivity: The biggest public health problem of the 21st century. Br J Sports Med. 2009;43:1-2.

5. Pedersen B. Exercise-induced myokines and their role in chronic diseases. Brain Behav Immun. 2011;25:811-6, https:// doi.org/10.1016/j.bbi.2011.02.010.

6. Autenrieth CS, Baumert J, Baumeister SE, Fischer B, Peters A, Döring A, et al. Association between domains of physical activity and all-cause, cardiovascular and cancer mortality. Eur J Epidemiol. 2011;26:91-9, https://doi.org/10.1007/ s10654-010-9517-6.

7. Wen CP, Wai JP, Tsai MK, Yang YC, Cheng TY, Lee MC, et al. Minimum amount of physical activity for reduced mortality and extended life expectancy: A prospective cohort study. Lancet. 2011;378:1244-53, https://doi.org/10.1016/ S040-6736(11)60749-6.

8. Byberg L, Melhus H, Gedeborg R, Sundström J, Ahlbom A, Zethelius B, et al. Total mortality after changes in leisure time physical activity in 50 year old men: 35 year follow-up of population based cohort. Br J Sports Med. 2009;43:482, https:// doi.org/10.1136/bmj.b688.
9. Brown WJ, McLaughlin D, Leung J, McCaul KA, Flicker L, Almeida OP, et al. Physical activity and all-cause mortality in older women and men. Br J Sports Med. 2012;46:664-8, https://doi.org/10.1136/bjsports-2011-090529.

10. Tudor-Locke C, Craig CL, Brown WJ, Clemes SA, de Cocker K, Giles-Corti B, et al. How many steps/day are enough? For adults. Int J Behav Nutr Phys Act. 2011;28:8-79, https:// doi.org/10.1186/1479-5868-8-79.

11. Tudor-Locke C. Steps to better cardiovascular health: How many steps does it take to achieve good health and how confident are we in this number? Curr Cardiovasc Risk Rep. 2010;4:271-6, https://doi.org/10.1007/s12170-010-0109-5.

12. Craig CL, Marshall AL, Sjostrom M, Bauman AE, Booth ML, Ainsworth BE, et al. International physical activity questionnaire: 12-country reliability and validity. Med Sci Sports Exerc. 2003;35:1381-95, https://doi.org/10.1249/ 01.MSS.0000078924.61453.FB.

13. De Cocker KA, de Bourdeaudhuij IM, Cardon GM. What do pedometer counts represent? A comparison between pedometer data and data from 4 different questionnaires. Public Health Nutr. 2009;12:74-81, https://doi.org/10.1017/ S1368980008001973.

14. International Physical Activity Questionnaire. Guidelines for data processing and analysis of the International Physical Activity Questionnaire (IPAQ) - Short and long forms 2005 [Internet] [cited 2016 June 9]. Available from: https://sites. google.com/site/theipaq.

15. Mitsui T, Barajima T, Kanachi M, Shimaoka K. Daily walking activity among male office workers in a rural town in northern Japan. J Physiol Anthropol. 2010;29:43-6, https://doi. org/10.2114/jpa2.29.43.

16. Nawata K, Ishida H, Yamashita N, Uenishi K. [Relationship between the number of steps taken and body mass index for male workers in the metropolitan area]. Sangyo Eiseigaku Zasshi. 2006;48:176-82, https://doi.org/10.1539/ sangyoeisei.48.176. Japanese.

17. Nicaise V, Crespo NC, Marshall S. Agreement between the IPAQ and accelerometer for detecting intervention-related 
changes in physical activity in a sample of Latina women. J Phys Act Health. 2014;11(4):846-52, https://doi.org/ 10.1123/jpah.2011-0412.

18. Sebastiao E, Gobbi S, Chodzko-Zajko W, Schwingel A, Papini CB, Nakamura PM, et al. The International Physical Activity Questionnaire-long form overestimates selfreported physical activity of Brazilian adults. Public Health. 2012;126:967-75, https://doi.org/10.1016/j.puhe.2012.07.004.

19. Bohannon R. Number of pedometer-assessed steps taken per day by adults: A descriptive meta-analysis. Phys Ther. 2007;87:1642-50, https://doi.org/10.2522/ptj.20060037.

20. Tudor-Locke C, Craig CL, Aoyagi Y, Bell RC, Croteau KA, de Bourdeaudhuij I, et al. How many steps/day are enough? For older adults and special populations. Int J Behav Nutr Phys Act. 2011;8:80, https://doi.org/10.1186/1479-5868-8-80.

21. Harris TJ, Owen CG, Victor CR, Adams R, Cook DG. What factors are associated with physical activity in older people, assessed objectively by accelerometry? Br J Sports Med. 2009;43:442-50, https://doi.org/10.1136/bjsm.2008.048033.

22. Bennett GG, Wolin KY, Puleo E, Emmons KM. Pedometer-determined physical activity among multiethnic low-income housing residents. Med Sci Sports Exerc. 2006;38(4): 768-73, https://doi.org/10.1249/01.mss.0000210200.87328.3f.

23. Ayabe M, Yahiro T, Yoshioka M, Higuchi H, Higaki Y, Tanaka H. Objectively measured age-related changes in the intensity distribution of daily physical activity in adults. J Phys Act Health. 2009;6:419-25, https://doi.org/10.1123/ jpah.6.4.419.
24. Dumith SC, Hallal PC, Reis RS, Kohl HW. Worldwide prevalence of physical inactivity and its association with human development index in 76 countries. Prev Med. 2011;53:24-8, https://doi.org/10.1016/j.ypmed.2011.02.017.

25. Ng SW, Norton EC, Popkin BM. Why have physical activity levels declined among Chinese adults? Findings from the 1991-2006 China Health and Nutrition Surveys. Soc Sci Med. 2009;68:1305-14, https://doi.org/10.1016/j.socscim ed.2009.01.035.

26. Bassett DR, Schneider PL, Huntington GE. Physical activity in an Old Order Amish Community. Med Sci Sports Exerc. 2004;36:79-85, https://doi.org/10.1249/01. MSS.0000106184.71258.32.

27. Hamilton SL, Clemes SA, Griffiths PL. UK adults exhibit higher step counts in summer compared to winter months. Ann Hum Biol. 2008;35:154-69, https:/doi. org/10.1080/03014460801908058.

28. McKee DP, Murtagh EM, Boreha CA, Nevill AM, Murphy MH. Seasonal and annual variation in young children's physical activity. Med Sci Sports Exerc. 2012;44:1318-24, https://doi.org/10.1249/MSS.0b013e3182464db5.

29. Pal S, Cheng C, Ho S. The effect of 2 different health messages on physical activity levels and health in sedentary overweight, middle-aged women. BMC Public Health. 2011;11:204, https://doi.org/10.1186/1471-2458-11-204

30. Wesołowska K, Czarkowska-Pączek B. Increasing the amount of walking may help prevent cardiovascular disease. Kardiol Po. 2013;71:318, https://doi.org/10.5603/KP. 2013.0054

This work is available in Open Access model and licensed under a Creative Commons Attribution-NonCommercial 3.0 Poland License - http://creativecommons.org/ licenses/by-nc/3.0/pl/deed.en. 